bility by itself, afterwards made by $B$. Stewart ; and so I failed to perceive that a soda flame which emits bright $\mathrm{D}$ must on that very account absorb light of the same refrangibility.

"When Foucault, whom I met at dinner at Dr. Neil Arnott's, when he came to receive the Copley Medal in 1855 , told me of his discovery of the absorption and emission of $\mathrm{D}$ by a voltaic arc, I was greatly struck with it. But though I had pictured to my mind the possibility of emitting and absorbing light of the same refrangibility by the mechanism of a system of piano strings tuned to the same pitch, which would, if struck, give out a particular note, or would take it up from the air at the expense of the aërial vibrations, I did not think of the extension of Prevost's theory, afterwards discovered by Stewart, nor perceive that the emission of light of definite refrangibility necessitated (and not merely permitted) absorption of light of the same refrangibility.

"Reviewing my then thoughts by the light of our present knowledge, I see that my error lay in the erroneous chemical assumption that sodium could not be free in the flame of a spirit-lamp; I failed to perceive the extension of Prevost's theory, which would have come in conflict with that error.-Yours sincerely,

$$
\text { (Signed) }
$$

"To Chas. Whitmell, Esq."

"G. G. STOKES

"P.S., Dec. 31.-As Sir Wm. Thomson has referred in print to a conversation I had long ago with him on the subject, I take the opportunity of describing my recollection of the matter.

"I mentioned to him the perfect coincidence of bright and dark $D$, and a part at least of the reasons I had for attributing the latter to the vapour of sodium, using I think the dynamical illustration of the piano strings. mentioned also, on the authority of Sir David Brewster, another case of coincidence (as was then supposed, though it has since been shown to be only a casual near agreement) of a series of bright lines in an artificial source of light with dark lines in the solar spectrum, from which it appeared to follow that potassium was present in the sun's atmosphere. On hearing this Thomson said something to this effect: 'Oh then, the way to find what substances are present in the sun and stars is to find what substances give bright lines coincident with the dark lines of those bodies.' I thought he was generalising too fast; for though some dark lines might thus be accounted for, I was disposed to think that the greater part of the non-terrestrial lines of the solar spectram were due to the vapours of compound bodies existing in the higher and comparatively cool regions of the sun's atmosphere, and having (as we know is the case with peroxide of nitrogen and other coloured gases) the power of selective absorption changing rapidly and apparently capriciously with the refrangibility of the light.

"If (as I take for granted) Sir William Thomson is right as to the date [1852] when he began to introduce the subject into his lectures at Glasgow (Address at the Edinburgh Meeting of the British Association [1871], page xcv.), he must be mistaken as to the time when I talked with him about Foucault's discovery, for I feel sure I did not know it till 1855 . Besides, when I heard it from Foucault's mouth, it fell in completely, with my previous thoughts.

"I have never attempted to claim for myself any part of Kirchhoff's admirable discovery, and cannot help thinking that some of my friends have been over zealous in my cause. As, however, my name has frequently appeared in print in connection with it, I have been induced to put on paper a statement of the views I entertained and talked about, though without publishing.

"In ascribing to Stewart the discovery of the exten= sion of Prevost's law of exchanges, I do not forget that it was re-discovered by Kirchhoff, who, indeed, was the first to publish it in relation to light, though the transition from radiant heat to light is so obvious that it could hardly fail to have been made, as in fact it was made, by Stewart himself (see 'Proceedings of the Royal Society' vol. x. p. 385). Nor co I forget that it is to Kirchhoff that we owe the admirable application of this extended law to the lines of the solar spectrum."

\section{SCIENCE IN THE ARGENTINE REPUBLIC *}

THE fourth part of the Bulletin of the National Academy of Sciences recently founded at Cordova, in the Argentine Republic, completes the first volume of this remarkable work, of which we have previously given some account to our readers. $\dagger$ The present part is mainly occupied by the conclusion of a long article upon the vegetation of the little known province of Tucuman, in the interior of the Republic, by Dr. Hieronymus, commenced in a former number. This is based upon the observations made by the author during a long and extensive scientific journey in that province, and upon the collections amassed by Dr. Lorentz in the same districts in $187 \mathrm{x}$ and $\mathrm{I} 872$, which have been mainly determined by Prof. Grisebach, of Göttingen. A second important article is by Dr. D. A. Döring, and treats of the lard and freshwater Molluscs of the Argentine Republic, arnongst which are a considerable number of new species, and. several interesting novel forms discovered by the author. A third memoir, from the pen of Dr. Burmeister, treats of the abnormal Hymenopterous insects of the Linnean genus Mutilla, and forms a complete monograph of the native species of this group, which will be very acceptable to entomologists. By the chronicle appended to the number, we learn that the strife which has prevailed between the Director of the Academy and the six German professors originally imported for its constitution has terminated in the signal defeat of the latter. After the expulsion of about half the number, the remainder resigned, and their places have been filled by other professors from the same country, whom we trust Dr. Burmeister will find more tractable. That they are full. of work is evident by the contributions to science already published in the present volume, upon the successful completion of which we heartily congratulate the energetic and illustrious Director of the Academy of Natural Sciences of the Argentine Republic.

\section{SOME UNSOLVED PROBLEMS IN THE MANAGEMENT OF THE MARINE AQUA- RIUM}

$T T$ would be fatal to further progress in that direc. tion in which so much has been achieved during the last ten years, if the zoological conditions of even the most successful of existing marine aquaria were to be blindly accepted as incapable of improvement, and especially if further experiment in reference to the vexed question of aëration were to be barred by the assumption that any one of those rival systems which are typified in the practice of Brighton, Sydenham, or any other similar establishment, is necessarily the best which can be attained.

More discussion than it has yet received is due to the broad question whether the total or almost total exclusion of vegetation from public aquaria is based on necessity or philosophy; whether artificial may not be advantageously supplemented by this most natural and automatic mode of aëration; and the further question remains, to what extent must the conditions of the aquarium be modified, as regards circulation and introduction of air, in order to render practicable the establishment and maintenance of a healthy vegetation, if the propriety of its introduction

* "Boletin de la Academia Nacional de Ciencias exactas existente en la Universidad de Cordova." Entrega iv. (Buenos Ayres, 1875.)

+ See Nature, vol, xi, p. 253 . 